\title{
DYNAMICS OF AN ENZYME POLYMORPHISM IN THE ISOPOD, SPHAEROMA RUGICAUDA (LEACH). II. SEXUAL, GAMETIC AND FECUNDITY SELECTION
}

\author{
J. P. EDWARDS* AND D. J. HEATH \\ Department of Biology, University of Essex, Colchester, England
}

Received 1.ii.82

\section{SUMMARY}

The estuarine isopod Sphaeroma rugicauda (Leach) exhibits a diallelic polymorphism at the locus coding for the enzyme Pgi. An investigation carried out during the animal's breeding season (June-July) in 1979 and 1980 indicated that the animals were mating at random. It also showed the s/s-homozygote females to be the earliest to release offspring and to be the most fecund of the three genotypes $(f / f, f / s$ and $s / s)$. Further, data from the wild population in 1980 and laboratory experiments indicated that male s-gametes were selected against in $\mathrm{s} / \mathrm{s}$ females, resulting in offspring ratio distortions in $\mathrm{f} / \mathrm{s}$ (male) $\times \mathrm{s} / \mathrm{s}$ (female) crosses, in favour of heterozygotes. The net effect of these selective pressures did not, however, significantly alter the genotype frequencies (found in the offspring) from expected values.

\section{INTRODUCTION}

In the preceeding paper (Edwards and Heath, 1983) it was shown that the frequencies of Pgi genotypes in the isopod $S$. rugicauda varied according to a regular seasonal pattern. Evidence from laboratory experiments suggested that at least some of these changes were due to zygotic selection.

The present study is an investigation of the components of selection (sexual, gametic and fecundity) which may be operating on the Sphaeroma population during its annual breeding season.

\section{Methods}

\section{(i) Sexual selection}

Two approaches were adopted for the analysis of this component of selection. The first involved regularly visiting the study area at low tide during the mating season (the peak activity being the first three weeks in June) and collecting mating pairs. These were easily identifiable as the females carry the males on their backs for a considerable period of time during mating. Each pair was placed separately in a small glass container and taken back to the laboratory for electrophoresis (see Edwards, 1981, for further details). A sample of non-mating animals was also collected at the same time.

The second approach was carried out late in June on consecutive high tide periods. Samples of gravid females were collected with a sweep-net from mid-June to early July. These were kept in the laboratory in individual

* Present Address: The University of Texas, Health Science Centre at Houston, School of Public Health, P.O. Box 20186, Houston, Texas 77025, U.S.A. 
petri dishes of seawater and the date of release of offspring noted-normally the offspring were released over 3 to 4 days. Once all the offspring from a particular female were free-swimming, the female and one randomly chosen offspring were electrophoresed. From this experiment information could be derived on two lines of enquiry: firstly, differential release dates between genotypes; secondly, the transmission of male gametes, by comparing the allele frequencies in males (collected from the saltmarsh during the mating period) to those found in the randomly electrophoresed offspring. Only one offspring from each female was scored because the possibility of multiple mating makes uncertain the number of male chromosomes represented in a given brood.

\section{(ii) Gametic selection}

As mentioned in the previous paper (Edwards and Heath, 1983), crosses were set up between randomly selected males and virgin females derived from high tide samples. Once the offspring had been released in the laboratory ten were randomly chosen for electrophoresis. As the effect of laboratory conditions on mating and subsequent development of offspring were unknown, the data obtained from this experiment were compared to those obtained by electrophoresing ten offspring from mated females taken from the wild. The disadvantage of using wild-caught females was that the male parental genotype was unknown and had to be deduced from the offspring genotypes. A small margin of error is, therefore, introduced, in that if all ten offspring are of one genotype then the cross is either between homozygotes (and for this experiment scored as such), or a cross involving heterozygotes and homozygotes where the offspring genotype ratios are heavily distorted in favour of one genotype. In addition, if multiple mating is occurring in the wild (a phenomenon which could account for distortions in offspring genotype ratios), it should be revealed by a comparison of the two sets of data, as the females kept in captivity were each fertilised by only one male.

\section{(iii) Fecundity selection}

So as to reduce the possibility that laboratory conditions would affect the fecundities of female Sphaeroma, females were used which had been removed from the wild just before they were due to release their offspring. In the laboratory each female was measured and then placed in a petri dish of seawater. Once all the offspring had been released and counted the females were electrophoresed.

\section{Results}

\section{(i) Sexual selection}

The mating pairs were collected on 11.6.79 and between 31.5.80-4.6.80 respectively for the two breeding seasons occurring during this study. The discrepancy in the number of days spent collecting each year was because in 1979 only one visit to the saltmarsh coincided with mating, whereas in 1980 Sphaeroma were found to be mating on five consecutive days. 
To analyse whether random mating was occurring, two factors have to be taken into account. Firstly, whether the mating animals constitute a genetically distinct group from the non-mating animals and secondly, whether the mating animals are mating at random amongst themselves. Regarding the former, table 1 shows the genotype frequencies of mating and non-mating animals collected from the saltmarsh in the 1979 and 1980 breeding seasons. From the data it is apparent that there was no significant difference in Pgi genotype frequencies between mating and non-mating animals.

\section{TABLE 1}

Chi ${ }^{2}$ Comparison of Pgi genotype frequencies in mating and non-mating animals from the two breeding seasons (1979 and 1980)

\begin{tabular}{clccccc}
\hline Date & Sample type & $\begin{array}{c}\text { Sample } \\
\text { size }\end{array}$ & $\mathrm{f} / \mathrm{f}$ & $\begin{array}{c}\text { Genotype frequency } \\
\mathrm{f} / \mathrm{s}\end{array}$ & $\mathrm{s} / \mathrm{s}$ & $\left(\begin{array}{c}\chi^{2} \\
(2 \mathrm{df})\end{array}\right.$ \\
\hline 11.6 .79 & Non-mating & 100 & 0.3500 & 0.4600 & 0.1900 & \multirow{2}{*}{1.363} \\
& Mating & 134 & 0.3881 & 0.4104 & 0.2015 & \\
4.6 .80 & Non-mating & 111 & 0.3784 & 0.4234 & 0.1982 & 1.183 \\
& Mating & 404 & 0.3787 & 0.4431 & 0.1782 & \\
\hline
\end{tabular}

The mating pair data were analysed by calculating the expected frequency of each cross (assuming random mating to be occurring) from the genotype frequencies of the males and females (found not to be significantly different from each other) collected during the breeding period, and comparing this to the observed genotype frequencies of the mating pairs. The data for the 1979 and 1980 seasons are shown in table 2, from which it can be seen that there were no statistically significant deviations from expected values, indicating that random mating was occurring.

TABLE 2

Chi ${ }^{2}$ comparison of observed frequency of each mating combination to those expected if the population were mating at random (1979 and 1980 breeding seasons)

\begin{tabular}{|c|c|c|c|c|}
\hline \multirow[b]{2}{*}{ Cross } & \multirow[b]{2}{*}{$N$} & \multicolumn{2}{|c|}{ Frequency } & \multirow{2}{*}{$\begin{array}{c}x^{2} \\
(5 \mathrm{df})\end{array}$} \\
\hline & & Obs. & Exp. & \\
\hline \multicolumn{5}{|l|}{ 1979: } \\
\hline$f / f \times f / f$ & 12 & 0.1791 & $0 \cdot 1663$ & \multirow{6}{*}{$1 \cdot 185$} \\
\hline $\mathrm{f} / \mathrm{f} \times \mathrm{f} / \mathrm{s}$ & 19 & 0.2836 & 0.3217 & \\
\hline $\mathrm{f} / \mathrm{f} \times \mathrm{s} / \mathrm{s}$ & 9 & 0.1343 & $0 \cdot 1611$ & \\
\hline $\mathrm{f} / \mathrm{s} \times \mathrm{f} / \mathrm{s}$ & 12 & 0.1791 & 0.1559 & \\
\hline$f / s \times s / s$ & 12 & $0 \cdot 1791$ & $0 \cdot 1560$ & \\
\hline $\mathbf{s} / \mathbf{s} \times \mathbf{s} / \mathbf{s}$ & 3 & 0.0448 & $0 \cdot 0390$ & \\
\hline \multicolumn{5}{|l|}{ 1980: } \\
\hline$f / f \times f / f$ & 24 & 0.1188 & 0.1468 & \multirow{6}{*}{4.983} \\
\hline $\mathrm{f} / \mathrm{f} \times \mathrm{f} / \mathrm{s}$ & 74 & 0.3663 & 0.3058 & \\
\hline $\mathrm{f} / \mathrm{f} \times \mathrm{s} / \mathrm{s}$ & 31 & 0.1535 & $0 \cdot 1668$ & \\
\hline $\mathrm{f} / \mathrm{s} \times \mathrm{f} / \mathrm{s}$ & 37 & 0.1831 & 0.1591 & \\
\hline $\mathrm{f} / \mathrm{s} \times \mathrm{s} / \mathrm{s}$ & 31 & 0.1535 & $0 \cdot 1742$ & \\
\hline $\mathrm{s} / \mathrm{s} \times \mathbf{s} / \mathrm{s}$ & 5 & 0.0248 & 0.0473 & \\
\hline
\end{tabular}


The females collected over three high tide periods during the breeding season could be conveniently divided into two batches in both years, depending on the release dates of their first offspring. In both 1979 and 1980 there was a batch of early releasing females (6.7.79-10.7.79 and 20.6.80-28.6.80) which comprised 31 per cent and 32 per cent of the total releasing females for the two years, respectively. After this initial period of activity, there was a lull of four to six days in which no (1979) or few (1980) females started releasing offspring before any large number of females began releasing offspring again. This second period of release (16.7.79-10.8.79 and approximately $2.7 .80-2.8 .80)$ was much longer in duration and incorporated approximately two-thirds of the females.

The allele frequencies of the females derived from these two distinctive release periods are shown in table 3 . The data show that in the early release periods Pgi-s is the more common allele, this situation being reversed in the late breeding period. This result would indicate that the $\mathrm{s} / \mathrm{s}$ homozygous females are releasing offspring first and, if the gestation periods are the same for all three Pgi genotypes (which is not known) that they are mating earlier than the $f / s$ and $f / f$ genotypes.

TABLE 3

Pgi allele frequencies of the early and late releasing females (1979 and 1980 data)

\begin{tabular}{|c|c|c|c|c|}
\hline & & Allele & dencies & $\begin{array}{l}\text { Heterogeneity }\left(x^{2}\right) \\
\text { between early and late }\end{array}$ \\
\hline & $N$ & f & $\mathbf{s}$ & release periods \\
\hline 1979 & & & & \\
\hline Early release period & 27 & 0.4815 & 0.5185 & $p<0.5$ \\
\hline Late release period & 60 & 0.6583 & $0 \cdot 3417$ & $(1 \mathrm{df})$ \\
\hline Total & 87 & 0.6035 & 0.3965 & \\
\hline 1980 & & & & \\
\hline Early release period & 40 & 0.4875 & 0.5125 & $p<0.5$ \\
\hline Late release period & 86 & 0.6105 & $0 \cdot 3895$ & $(1 \mathrm{df})$ \\
\hline Total & 126 & 0.5714 & 0.4286 & \\
\hline
\end{tabular}

The final point to be made concerning the data is derived from the analysis of male gamete transmission. Using the mother/random offspring data, the ratio of offspring genotypes produced by the three female genotypes can be calculated (table 4). If random mating is occurring, then the frequency of the fast allele (or conversely, the slow allele) in the breeding males should be transmitted equally efficiently to the offspring regardless of the genotype of the female (providing there is no gametic selection and that all male genotypes are available for mating throughout the breeding period). The penultimate column in table 4 shows the transmitted $\mathrm{f}$ allele frequencies. These frequencies were compared (using chi ${ }^{2}$ ) to the frequency of $\mathrm{f}$ in the males and were found not to be significantly different. This is, therefore, further evidence suggesting that no selection is occurring in the wild population of Sphaeroma. 
TABLE 4

Transmission of male gametes to the offspring

(The final column gives the chi ${ }^{2}$ values for a comparison between the transmitted male $f$ allele frequencies and the frequencies of the f allele found in the males during the breeding season)

\begin{tabular}{|c|c|c|c|c|c|c|}
\hline & \multirow[b]{2}{*}{$N$} & \multicolumn{3}{|c|}{ Offspring genotypes } & \multirow{2}{*}{$\begin{array}{l}\text { Transmitted male } \\
\mathrm{f} \text { allele frequency }\end{array}$} & \multirow{2}{*}{$(1 \mathrm{df})$} \\
\hline & & $\mathrm{f} / \mathrm{f}$ & $\mathrm{f} / \mathrm{s}$ & $\mathbf{s} / \mathbf{s}$ & & \\
\hline \multicolumn{7}{|l|}{$\begin{array}{l}1979 \\
\text { Female } \\
\text { genotype }\end{array}$} \\
\hline $\mathrm{f} / \mathrm{f}$ & 35 & 12 & 13 & - & 0.6286 & 0.0773 \\
\hline$f / s$ & 35 & 10 & 15 & 10 & 0.5000 & 1.634 \\
\hline s/s & 17 & - & 12 & 5 & 0.7059 & 0.7158 \\
\hline \multicolumn{7}{|l|}{$\begin{array}{l}1980 \\
\text { Female } \\
\text { genotype }\end{array}$} \\
\hline$f / f$ & 44 & 27 & 17 & - & 0.6136 & 0.2278 \\
\hline$f / s$ & 56 & 19 & 24 & 13 & 0.6071 & 0.1937 \\
\hline s/s & 26 & - & 16 & 10 & 0.6154 & 0.1482 \\
\hline
\end{tabular}

$\dagger$ Breeding male $f$ allele frequency $(1979)=0.6056$

Breeding male $f$ allele frequency $(1980)=0.5781$.

\section{(ii) Gametic selection}

In the previous paper (Edwards and Heath, 1983) it was demonstrated that the Pgi polymorphism was genetically determined, crosses between like homozygotes and unlike homozygotes yielding the expected results. Table 5 summarises the data for the other combinations derived from both laboratory crosses and pregnant females taken from the wild in 1979 and 1980.

In both sets of laboratory and wild data the crosses between $f / f \times f / s$ and $\mathrm{f} / \mathrm{s} \times \mathrm{f} / \mathrm{s}$ gave no significant deviations from $50: 50 \mathrm{f} / \mathrm{f}: \mathrm{f} / \mathrm{s}$ and $25: 50: 25 \mathrm{f} / \mathrm{f}: \mathrm{f} / \mathrm{s}: \mathrm{s} / \mathrm{s}$ ratios as would be expected. However, nonMendelian results were obtained for the cross between the heterozygote (f/s) and the s/s homozygote. In both sets of laboratory data for 1979 and 1980 and for the 1980 wild females, there was a deficit of s/s homozygotes. Furthermore, if the 1979 and 1980 wild data and the 1980 laboratory data (for which the appropriate information is available) are divided into those crosses where the $\mathrm{s} / \mathrm{s}$ is the female and vice versa (table 6 ), it is evident that it is only when the female is an s/s homozygote that this phenomenon occurs.

\section{(iii) Fecundity selection}

The data for fecundities were analyzed in relation to female size. Each female was placed in a $5 \mathrm{~mm}$ size class and the overall fecundity difference between the Pgi genotypes tested using the Mann-Whitney U-test (table 7). The results for each size class, taken separately, in many cases showed no fecundity differences between the Pgi genotypes. This is probably due to the small sample sizes (the higher size classes contained so few individuals that it was not possible to test for fecundity differences between genotypes). 
TABLE 5

Comparison of observed and expected offspring genotype ratios from $f / f \times f / s, f / s \times f / s$, and $f / s \times s / s$ crosses (laboratory and wild data)

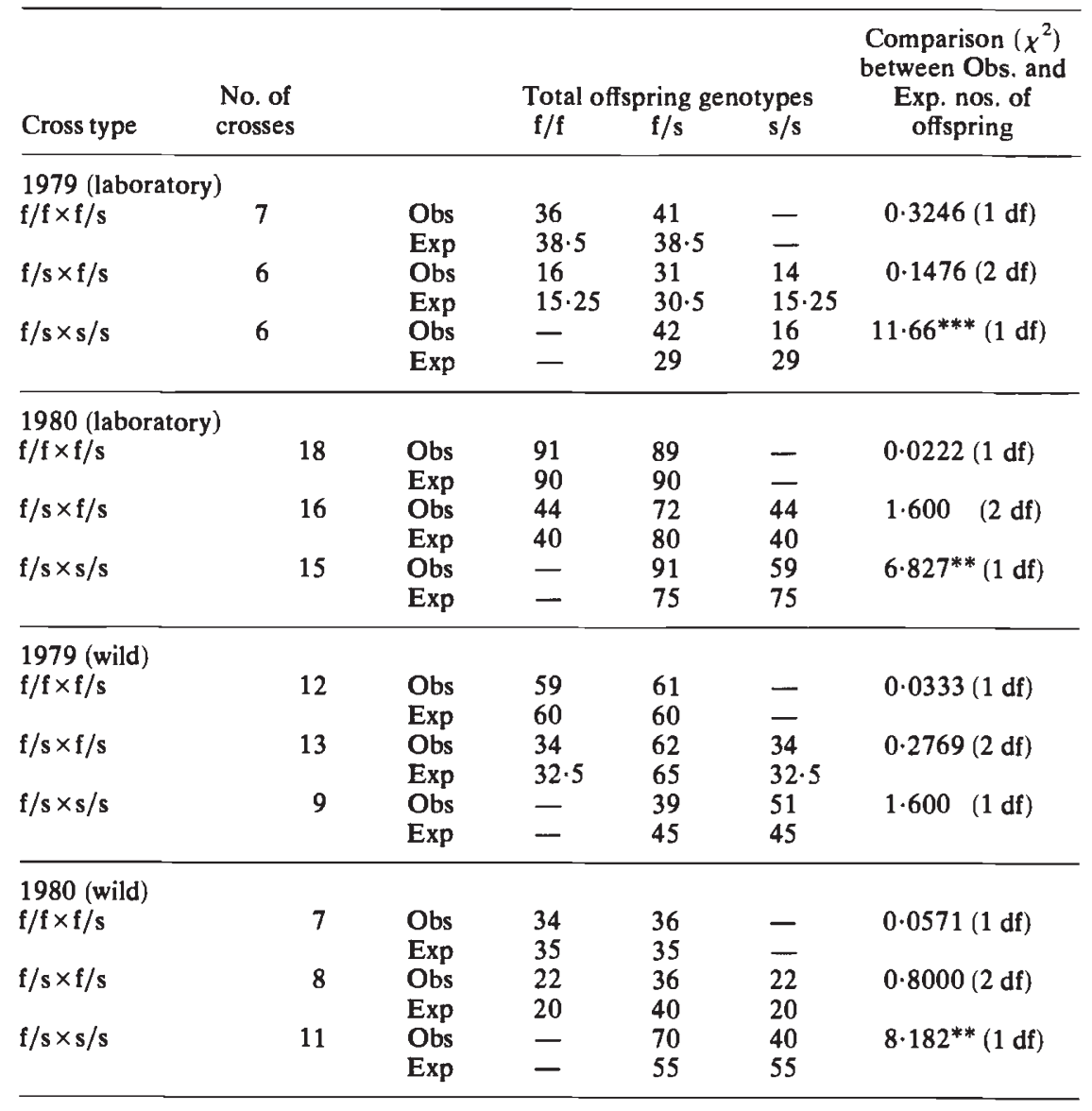

Where there were statistically significant results the differences were between the s/s homozygote and either or both of the other two genotypesthe $\mathrm{s} / \mathrm{s}$ homozygote being the more fecund. The one exception to this being the 4.1-4.5 mm size class in 1980 where the heterozygotes were significantly more fecund than the $\mathrm{f} / \mathrm{f}$ homozygote. Overall, however, the results indicated that in both years the s/s homozygote was significantly more fecund $(p<0.001)$ than either the $\mathrm{f} / \mathrm{f}$ or $\mathrm{f} / \mathrm{s}$ genotypes (which had similar fecundities). The degree of difference was of the order of 20 per cent.

\section{Discussion}

The data from the previous paper (Edwards and Heath, 1983) indicate that the frequencies of the Pgi genotypes in the wild population vary in response to differential seasonal selection. Survivorship experiments in the laboratory demonstrating that the observed frequency increase in the s/s homozygotes during the winter can be explained by this genotype being 
TABLE 6

Analysis of offspring genotype ratios derived from $\mathrm{f} / \mathrm{s} \times \mathrm{s} / \mathrm{s}$ crosses, comparison between $\mathrm{f} / \mathrm{s}$ (male) $\times s / s$ (female) and $\mathrm{f} / \mathrm{s}(\mathrm{female}) \times s / s$ (male)

\begin{tabular}{|c|c|c|c|c|c|}
\hline $\begin{array}{l}\text { Cross type } \\
\text { male female }\end{array}$ & $\begin{array}{l}\text { No. of } \\
\text { crosses }\end{array}$ & & $f / s$ & $\mathbf{s} / \mathbf{s}$ & $\begin{array}{c}\text { Comparison }\left(\chi^{2}\right) \\
\text { between Obs. and } \\
\text { Exp. nos. of offspring }\end{array}$ \\
\hline \multicolumn{6}{|l|}{1980 (laboratory) } \\
\hline$f / s \times s / s$ & 9 & $\begin{array}{l}\text { Obs } \\
\text { Exp }\end{array}$ & $\begin{array}{l}58 \\
45\end{array}$ & $\begin{array}{l}32 \\
45\end{array}$ & $7 \cdot 512^{* *}(1 \mathrm{df})$ \\
\hline$s / s \times f / s$ & 6 & $\begin{array}{l}\text { Obs } \\
\text { Exp }\end{array}$ & $\begin{array}{l}33 \\
30\end{array}$ & $\begin{array}{l}27 \\
30\end{array}$ & $0.6000 \quad(1 \mathrm{df})$ \\
\hline \multicolumn{6}{|l|}{1979 (wild) } \\
\hline $\mathrm{f} / \mathrm{s} \times \mathrm{s} / \mathrm{s}$ & 5 & $\begin{array}{l}\text { Obs } \\
\text { Exp }\end{array}$ & $\begin{array}{l}22 \\
25\end{array}$ & $\begin{array}{l}28 \\
25\end{array}$ & $0.7200 \quad(1 \mathrm{df})$ \\
\hline$s / s \times f / s$ & 4 & $\begin{array}{l}\text { Obs } \\
\text { Exp }\end{array}$ & $\begin{array}{l}17 \\
20\end{array}$ & $\begin{array}{l}23 \\
20\end{array}$ & $0.9000 \quad(1 \mathrm{df})$ \\
\hline $\begin{array}{l}1980 \text { (wild) } \\
\mathrm{f} / \mathrm{s} \times \mathrm{s} / \mathrm{s}\end{array}$ & 5 & Obs & 36 & 14 & $9 \cdot 680^{* *}(1 \mathrm{df})$ \\
\hline$s / s \times f / s$ & 6 & $\begin{array}{l}\text { Obs } \\
\text { Exp }\end{array}$ & $\begin{array}{l}34 \\
30\end{array}$ & $\begin{array}{l}26 \\
30\end{array}$ & $1.067 \quad(1 \mathrm{df})$ \\
\hline
\end{tabular}

TABLE 7

Fecundity differences between the three female genotypes. Probability values comparing the fecundities are shown between the appropriate columns

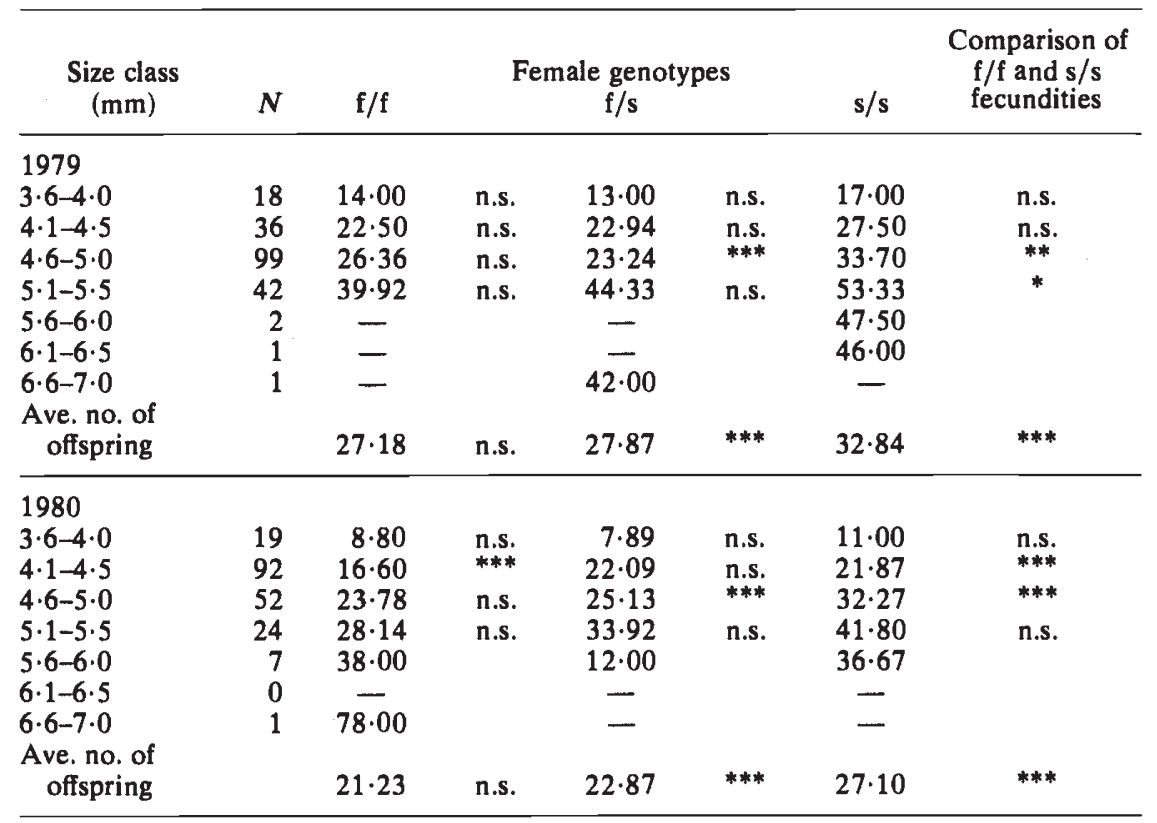

\footnotetext{
${ }^{*} p<0.05$.

$* * p<0.01$.

$* * * p<0 \cdot 001$.
} 
able to tolerate and survive the low water temperatures experienced by the animals during this period.

In the present study an analysis of the components of selection associated with reproduction (sexual, gametic and fecundity selection) revealed significant differences in the dates on which offspring were released, female fecundities and offspring genotype ratios from certain matings. Furthermore, these differences were associated with the Pgi-s/s homozygote in that the $\mathrm{s} / \mathrm{s}$ females appear to mate and release offspring earlier than the other two genotypes ( $\mathrm{f} / \mathrm{f}$ and $\mathrm{f} / \mathrm{s}$ ), produce more offspring and at least in the 1980 breeding season are selected against in $\mathrm{s} / \mathrm{s}$ female $\times \mathrm{f} / \mathrm{s}$ male matings.

The early release of offspring by s/s females and their higher fecundity would support the hypothesis that as the s/s genotype survives preferentially during the winter, they are in a "better" physiological condition to breed. This would presumably be of more significance to female Sphaeroma in that the metabolic demand of producing eggs would be greater than the demands of producing sperm in males. This is borne out by the data on sexual selection in that all three male genotypes would appear to be available for mating throughout the breeding season. In their studies on the freshwater cladoceran Daphnia magna, Hebert (1974) and Young (1975) have reported that frequency changes at two enzyme loci (malate dehydrogenase and esterase-1) showed reasonable concordance with the changes expected on the basis of genotype differences in egg production. Hebert (1978) has suggested that egg production may well be related to other fitness components, the most fecund genotype in the population possessing the most "spare" energy, either because it has collected more food or utilised it more efficiently. Therefore, if juveniles of this genotype share the same advantage then they could well survive harsh conditions better and reproduce earlier than juveniles of the other genotypes. This hypothesis would fit well the situation observed in the Sphaeroma population.

Zygotic selection favouring the s-allele during the winter would ultimately lead to the extinction of the f-allele in the population without a counter-balancing selective force. This is provided, in part, by the selection against the s-allele in $\mathrm{f} / \mathrm{s} \times \mathrm{s} / \mathrm{s}$ matings. As this phenomenon is only observed in $\mathrm{f} / \mathrm{s}$ male $\times \mathrm{s} / \mathrm{s}$ female crosses it would indicate either that male s-gametes are less successful in fertilising eggs in female s/s homozygotes (gametic selection) or that s/s zygotes are selected against at the pre-partum zygote stage (early zygotic selection). If the latter is true then the fecundities of the $s / s$ homozygotes would be expected on average to be less than the $f / f$ and $\mathrm{f} / \mathrm{s}$ genotypes. The fecundity data suggests the opposite (i.e., the s/s homozygotes are the most fecund of the three genotypes) which favours the hypothesis that the s-gametes are selected against by $s / s$ females.

Further this selection must be associated in some way with the physiology of female s/s homozygotes as no offspring ratio distortions were observed in other mating combinations involving $\mathrm{f} / \mathrm{s}$ males.

The significance of this gametic selection to the present study is that it provides an opposing selective force to the zygotic selection favouring the s-allele and this may provide a partial explanation for the apparent temporal stability of the Pgi polymorphism. Gametic selection has been only infrequently recorded in animal species being probably more common in 
plants where the alleles are more likely to be expressed in the differentiated gametophyte stage. However, in natural populations of several Drosophila species a genetic variant has been observed which subverts the normal processes of meiosis and sex cell formation and thus gained a selective advantage. Males with the so-called "sex ratio" $X$ chromosome produce functioning spermatazoa most or all of which carry $\mathrm{X}$ chromosomes. Thus when crossed to any female the offspring consist almost exclusively of females. Obviously unopposed by some other selective agent the "sex ratio" X chromosomes would take over the population producing populations consisting only of females. This is found not to occur in the Drosophila species studied, the reasons for this still being conjectural. A similar situation is observed at the $t$-locus in the house mouse, Mus musculus. Dunn and his co-workers (Dunn, 1960; Dunn, 1964; Bennett and Dunn, 1964; Dunn and Bennett, 1971) have found that a male mouse heterozygous for a t-mutant and its "normal" allele generates many more functioning spermatozoa with the t-mutant than with the normal allele. In this case, however, the spread of the mutant appears to be opposed by the homozygous lethality of many t-alleles.

Of especial interest to the present study was the work carried out by Christiansen et al., (1973) on the esterase-III polymorphism in the eelpout Zoarces viviparus. Their analysis provided significant evidence of zygotic selection in the period between the foetal and adult stage. Their observations indicating that the zygotic gene frequency shift (due to zygotic selection through either differential survival or differential emigration) was counteracted by either male sexual or male gametic selection.

The hypothesis that the Pgi polymorphism is maintained in Sphaeroma by a balance between zygotic and gametic selection is, however, complicated by the data on fecundity selection favouring the s-allele. This raises the general point of the difficulty in ascertaining the total fitness of an allele or genotype amongst a complexity of often counterbalancing selective forces. In their study of selection at the phosphoglucose mutase (Pgm-1) and malic enzyme (Me-2) loci (both diallelic loci) in Drosophila pseudoobscura Marinkovic and Ayala (1975) found that the relative fitnesses of the genotypes could be reversed when different fitness components were considered. For example, double homozygotes for the most common allele of Pgm and Me were found to have more than twice the fecundity of the double homozygotes for the rare Pgm and Me alleles, yet the male mating capacity of the latter was much greater than the former. Similarly, the Pgm homozygotes for the common allele were superior to the Pgm heterozygotes in female fecundity but inferior to them in egg-to-adult survival under competitive conditions and in rate of development. Kojima and Tobari 1969) found differences in larval viabilities among genotypes at the alcohol dehydrogenase locus in Drosophila melanogaster and suggested that "such viability differences may be counterbalanced with some other fitness component differences". Interestingly, Sassaman (1978), in his study of a lactate dehydrogenase polymorphism in another isopod Porcellio scaber, put forward evidence (derived from an analysis of the polymorphism using motheroffspring genotype comparisons) suggesting that the animals exhibited partial assortative mating-leading to a deficit of heterozygotes in the progeny. However, comparisons of progeny genotype distributions from the same populations indicated a superior post-partum viability of heterozy- 
gotes relative to homozygotes. Therefore, the distortion of progeny genotype distributions (by assortment) was apparently counteracted by subsequent heterozygous advantage (in survival).

Certainly the temporal stability in allele frequencies in Sphaeroma would suggest that the Pgi polymorphism is in selective balance. However, as some of these selective forces are components of the physio-chemical environment it can be envisaged that a series of atypical environmental fluctuations would alter the balance between the $f$ and $s$ alleles. To test this hypothesis it would be necessary to monitor genetic changes in the Sphaeroma population over a number of years, in which it would be reasonable to assume that the animals would experience more extreme environmental fluctuations than in the present 27 -month study.

\section{REFERENCES}

BENNETT, D. AND DUNN. L. C. 1964. Repeated occurrances in the mouse of lethal alleles of the same complementation group. Genetics, 49, 949-958.

CHRISTIANSEN, F. B., FRYDENBERG, O. AND SIMONSEN, V. 1973. Genetics of Zoarces populations. IV. Selection component analysis of an esterase polymorphism using population samples including mother-offspring combinations. Hereditas, 73, 291-304.

DUNN, L. C. 1960 . Variations in the transmission ratios of alleles through egg and sperm in Mus musculus. Amer. Natur, 44, 358-393.

DUNN, L. C. 1964. Abnormalities associated with a chromosome region in the mouse. I. Transmission and population genetics of the $t$-region. Science, 144, 260-263.

DUNN, L. C. AND BENNETT, D. 1971. Lethal alleles near locus $T$ in house mouse populations on the Jutland peninsular, Denmark. Evolution, 25, 451-453.

EDWARDS, J. P. 1981. Analysis of an Enzyme Polymorphism in the Isopod Sphaeroma rugicauda (Leach). Ph.D. Thesis, University of Essex.

EDWARDS, J. P. AND HEATH, D. J. 1983. Dynamics of an enzyme polymorphism in the isopod, Sphaeroma rugicauda. I. Temporal variation in genotype frequencies. Heredity, 51 .

HEBERT, P. D. N. 1974. Ecological differences between genotypes in a natural population of Daphnia magna. Heredity, 33, 327-337.

HEBERT, P. D. N. 1978. The population biology of Daphnia (Crustacea, Daphnidae). Biol. $\operatorname{Rev}, 53,387-426$.

KOJIMA, K. AND TOBARI, Y. N. 1969. The pattern of viability changes associated with genotype frequency at the alcohol dehydrogenase locus in a population of Drosophila melanogaster. Genetics, 61, 201-209.

MARINKOVIC, D. AND AYALA, F. J. 1975. Fitness of allozyme variants in Drosophila pseudoobscura. I. Selection at the Pgm- 1 and $M e-2$ loci. Genetics, 79, 85-95.

SASSAMAN, C. 1978. Dynamics of a lactate dehydrogenase polymorphism in the woodlouse Porcellio scaber Latr.: evidence for partial assortative mating and heterosis in natural populations. Genetics, 88, 591-609.

YOUNG, J. P. W. 1975. Enzyme Polymorphism and Reproduction in Daphnia magna. Ph.D. Thesis, University of Cambridge. 